\title{
Cooperation Versus Competition Effects on Information Sharing and Use in Group Decision-Making
}

\author{
Claudia Toma ${ }^{1 *}$ and Fabrizio Butera ${ }^{2}$ \\ ${ }^{1}$ Université libre de Bruxelles \& Tilburg University \\ ${ }^{2}$ University of Lausanne
}

\begin{abstract}
Information processing in groups has long been seen as a cooperative process. In contrast with this assumption, group members were rarely found to behave cooperatively: They withhold unshared information and stick to initial incorrect decisions. In the present article, we examined how group members' cooperative and competitive motives impact on group information processing and propose that information sharing and use in groups could be seen as strategic behavior. We reviewed the latest developments in the literature investigating different forms of strategic information processing and their underlying mechanisms. This review suggests that explicit cooperative goals are needed for effective group decision-making.
\end{abstract}

When complex problems are to be solved, groups are often used to make decisions. Juries decide about the guilt of an alleged murderer, selection panels about the best candidate for a new position, industrial executive panels about the development of a new factory, and boards of managers about future business plans. One reason for using groups is that its members should possess a larger pool of information, knowledge, and skills than a single person, which is likely to lead to more informed decisions. This ideal perspective on the role of groups has had a strong influence on the research conducted for the last 25 years in the area of group decision-making (for a review, see Stasser \& Titus, 2003), developed on the assumption that group members work cooperatively when making decisions (Wittenbaum, Hollingshead, \& Botero, 2004). The present article reconsiders this classic cooperative assumption and reviews recent literature suggesting that group decision-making situations involve a mixture of cooperative and competitive motives that affect the extent to which members share and use their information.

\section{Information Sharing and Use in Group Decision-Making}

Group decision-making reflects group-level information processing (Hinsz, Tindale, \& Vollrath, 1997) that involves both information sharing and information use. Information sharing refers to the pooling of all informational resources that group members possess, which can be shared information, namely information known to all group members, and unshared information, namely information known only by one or some group members (Stasser \& Titus, 1985). Unshared information is the key element that allows groups to reach decisions of superior quality, as compared to individual decision, if their members share this information (Stasser \& Titus, 2003): Indeed, pooling unshared information allows the group to work with a body of information which is larger than that of each single member. Research on information pooling, however, has repeatedly shown that group members pool and repeat more shared than unshared information, a phenomenon called information-sampling bias (Stasser \& Titus, 1985, 1987; for a meta-analysis, see Lu, Yuan, \& McLeod, 2012). This bias has been mainly attributed to the superior probability of shared information to be mentioned during discussions, because directly 
related to the number of group members who posses that information (Stasser, Taylor, \& Hanna, 1989). For example, in a three-member group, shared information can be mentioned three times, while unshared information only once. However, another recent meta-analysis on information exchange conducted by Reimer, Reimer, and Czienskowski (2010) revealed that the bias in favor of shared information is only half the value predicted by the probabilitysampling model. Another explanation for the information-sampling bias relies on the notion that shared information appears more valuable than unshared information because all members in the groups possess it (Wittenbaum, Hubbell, \& Zuckerman, 1999).

Groups are not only poor at sharing their information, but also at processing the available information. Research has found that even when all pieces of information are discussed, group members still have difficulties in making the best decision (Mojzisch, Grouneva, \& SchulzHardt, 2010). Two biases in the evaluation of information have been identified in the literature. First, people evaluate their own information more favorably than others' information (an effect called "ownership bias"; Van Swol, Savadori, \& Sniezek, 2003). For example, in one study with real group discussion, participants judged their own discussed unshared information as more important than others' discussed unshared information (Chernyshenko, Miner, Baumann, \& Sniezek, 2003). In another study, participants rated the information received before the group discussion (own information) as more valid than the information received during the discussion (others' information; Van Swol et al., 2003).

Second, when considering others' information, people evaluate more positively information that is consistent, rather than inconsistent, with their initial preference (an effect called "preference effect"; Greitemeyer \& Schulz-Hardt, 2003). People also tend to discuss more often the information that is consistent with their initial decision (Mojzisch et al., 2010). One reason is that consistent information is more salient and more readily accessible from memory than inconsistent information (Greitemeyer \& Schulz-Hardt, 2003). More recently, Faulmüller, Kerschreiter, Mojzisch, \& Schulz-Hardt (2010) argued that sharedness and preference for consistent information are often confounded in group decision-making situations, which leads to a preference-consistent information sharing. Both the ownership bias and the preference effect were found to be responsible for poor decisions quality (Greitemeyer \& SchulzHardt, 2003; Toma, Bry, \& Butera, 2013), beyond unshared information pooling (Toma \& Butera, 2009).

Notwithstanding the wealth of research on information processing in groups, an important question remains: If group members are motivated to cooperate, with the aim of reaching the best possible decision, why would they neglect crucial unshared information and display such egocentric biases as the ownership bias and the preference effect? The aim of this article is to shed new light on these phenomena using recent experimental research that provides evidence that information sharing and use in groups do not necessarily reflect biases in information processing but rather deliberate and strategic behavior.

\section{From Cooperation to Mixed-Motives in Group Decision-Making}

Previous research provided important insights regarding the role of information processing in group decision-making (e.g., Larson, Christensen, Abbott, \& Franz, 1996; Stasser \& Stewart, 1992; Stasser, Stewart, \& Wittenbaum, 1995; Stasser \& Titus, 2003; Stewart \& Stasser, 1998), but very little of this research integrated the role of motivation. More recently, theoretical contributions (De Dreu, Nijstad, \& van Knippenberg, 2008; Nijstad \& De Dreu, 2012; Toma, Vasiljevic, Oberlé, Augustinova, \& Butera 2012) and empirical research (Toma \& Butera, 2009; Steinel, Utz, \& Koning, 2010) suggested that the assumption that groups cooperate in decision-making is not warranted, and that cooperative and competitive motives might co-exist 
within the group. Indeed, it often happens that group members face a mixture of cooperative incentives to reach high-quality group decisions, as well as competitive incentives to do well personally, to attain a high status, or to prove their competence. Within the same group, some members may be motivated by cooperation and act in the interest of the group, while other members may be motivated by competition and only act in their own interest. For example, within a board of managers who must decide about future business plans, some managers will share the available information, while others might hide information disclosing personal interests (e.g., information supporting a specific solution if that solution implies that he/she would make less money). Given the complexity of the social settings that decision-making groups often face, some authors have proposed that earlier findings reflect mixed-motives rather than purely cooperative situations (Wittenbaum et al., 2004).

In particular, the Motivated Information Processing in Groups model (MIP-G; De Dreu et al., 2008) was developed to shed light on the role of different motivations in groups and expands the view of groups as information processors (Hinsz et al., 1997) to groups as motivated information processors. The model states that information processing in groups is driven by two orthogonal motivations, namely epistemic and social motivations. Epistemic motivation refers to individuals' "willingness to expend effort to achieve a thorough, rich and accurate understanding of the world, including the group task or decision problem at hand" (De Dreu et al., 2008 , p. 23). Social motivation refers to "individual preference for outcome distributions between oneself and other group members" (De Dreu et al., 2008, p. 23). Epistemic motivation influences the depth of information processing, while social motivation influences the various biases in information processing (De Dreu et al., 2008). Because the aim of the present article is to provide evidence that biases in information sharing and use can be viewed as strategic behavior, we will now focus on social motivations.

Social motivation is driven by both dispositional and situational variables. On the one hand, it is captured by individual differences in social value orientation (Messick \& McClintock, 1968; Van Lange, Otten, De Bruin, \& Joireman, 1997), reflecting group members' preference in resources allocation between self and others, which can vary from pro-social (members are interested to enhance joint resources) to pro-self (members are interested to enhance their relative advantage over others' resources). Social motivation is also captured by individual differences in achievement goals, in particular performance goals (Harackiewicz \& Sansone, 1991). More specifically, group members pursuing performance-approach goals strive to demonstrate their superiority by outperforming others (Dweck, 1986) and to show that they are right while others are wrong (Sommet et al., 2014), whereas members pursuing performance-avoidance goals try to avoid being inferior to others (Elliot \& McGregor, 2001) and seek consensus with others (Sommet et al., 2014).

On the other hand, social motivation can also be induced by situational cues like positive or negative goal interdependence (Johnson \& Johnson, 1989), collective versus individual incentives like rewarding the whole group or only some members (Pearsall, Christian, \& Ellis, 2010; Hayek, Toma, Oberlé, \& Butera, 2014), or by explicit instructions to cooperate or to compete (De Dreu et al., 2008). According to the MIP-G model, members who are motivated by cooperation should process information in a way that serves collective interests and the group's goal of making the best decision possible. On the contrary, members who are motivated by competition should process information in a way that fosters individual outcomes. For example, members motivated by competition should exchange less information contradicting their preferences and should react defensively when their own decisions are questioned (see also Nijstad \& De Dreu, 2012). In the remainder of this article, we will thus report research that supports the hypothesis that groups members share and use information as a function of their motivations. 


\section{Strategic Information Sharing in Groups}

\section{From hidden profiles to information pooling games}

The hidden profiles (Stasser \& Titus, 1985, 1987) have been extensively employed to investigate information sharing in groups. In this paradigm, group members need to decide among a series of alternatives (e.g., suspects in a murder), but each member is given only part of the information available about each alternative. The key pieces of information are given to different members (unshared information), while other pieces of information are given to all members (shared information). For this reason, shared information usually supports a different, inferior alternative than unshared information, which supports a superior alterative when discussed in groups. These are important features of the hidden profile paradigm, as they make sharing information necessary to reaching the optimal decision. For example, a group of three members has to decide who, among four suspects, is the person responsible for a road accident. Based on his/her unshared information, one group member decides that the guilty person is Mrs. Y. However, another group member has the information that the guilty person is a man, which invalidates the Mrs. Y solution. Based on his/her unshared information, this second group member decides that the guilty person is Mr. X, who is 53 years old. However, the third group member has the information that the guilty person is less than 30 years old, which invalidates the Mr. X solution. In the end, this group can decide who is the real guilty person (Mr. X's son) only if they pool their unshared information and eliminate all the suboptimal alternatives.

Most of previous studies using this paradigm assumed that group members cooperate toward the common goal of making the best group decision and therefore they should pool their information, and especially unshared information. In other words, it was expected that because members must cooperate and share their information, that they would necessarily behave that way (Wittenbaum et al., 2004). However, most studies using hidden profiles found that group members pooled less unshared than shared information and made decisions of poor quality (for a review, Lu et al., 2012). This suggests that group members failed to work cooperatively in a task that strongly required cooperation and information sharing. Although many valid explanations were proposed to account for this effect (such as sampling advantage of shared information [Stasser \& Titus, 1985], preference for consistent information [Greitemeyer and Schulz-Hardt (2003)], and mutual enhancement [Wittenbaum et al., 1999]), previous research overlooked that information sharing in groups could reflect deliberate behavior influenced by members' goals.

For this reason, several authors proposed that unshared information neglect might also be understood by taking into account the cooperative and competitive goals underlying this task (De Dreu et al., 2008; Nijstad \& De Dreu, 2012). The mere fact that hidden profiles imply cooperation does not mean that group members always act cooperatively (Wittenbaum et al., 2004). If group members are motivated by competition, which is a likely circumstance as discussed earlier, they should restrain the access to their valuable information, namely to unshared information.

Toma and Butera (2009) investigated this idea in a study with three-person groups who had to solve a hidden profile. They manipulated cooperative and competitive motives by telling participants either that their goal was to make the best decision as a group or to make the best decision as individual members. Participants were told in advance which information was shared and which information was unshared, a procedure that allowed to test whether information sharing reflects strategic behavior. Results showed that members in competition pooled less valuable, unshared information than members in cooperation, while no difference was found for shared information. Interestingly, the fact that members in competition pooled as much 
shared information as members in cooperation may indicate an attempt of group members to trigger others' cooperation and the unveiling of their unshared information.

More recently, researchers claimed that some hidden profiles and, more generally, the situations of information exchange share some features of social dilemmas (e.g., Kimmerle, Wodzicki, Jarodzka, \& Cress, 2011). Indeed, both in social dilemmas and in hidden profiles, collective interests could be at odds with private interests. For example, in some hidden profiles, members are made aware that information sharing serves collective interests but also individual ones (see below explanations about the information pooling game). If in those hidden profiles group members are motivated by competition (e.g., a member supports a decision alternative that favors him personally), it is tempting and convenient to use others' unshared information without contributing one's own unshared information. In this way, members avoid losing their competitive advantage, they spend less time and effort, and take advantage of other members' willingness to behave cooperatively and to share information (Kimmerle et al., 2011). Like in traditional social dilemmas, in those hidden profiles, group members are facing a situation in which it is always more self-advantageous in the short term to withhold information than to share it, which corresponds to a strategic behavior.

However, the hidden profile paradigm is not the perfect tool to test the strategic information processing prediction (Steinel et al., 2010). Among the limitations of this paradigm, the most problematic is that in hidden profiles, it is difficult to make a distinction between strategic withholding of unshared information and its neglect for other reasons (e.g., because it simply goes against people's initial preferences). Another issue is that in hidden profiles, group members are generally unaware of the information that needs to be shared to make a good decision (for an exception, see Toma \& Butera, 2009). Imagine a group of three friends who must decide which between two locations (Paris or London) is the best for their vacations. All members know six positive arguments about Paris (shared information), but each member knows three positive arguments about London (unshared information). If members share all the information, London would objectively be a better location (because the positive arguments would sum up to nine). However, if members are unaware that they posses unshared information, they might end up in choosing Paris for their vacation. To overcome this problem, Steinel et al. (2010) developed the information pooling game that incorporates one important feature of social dilemmas, namely that members are made aware that information sharing could serve both collective and individual interests. More specifically, in this paradigm, participants are told which information is shared and which is unshared, and also which information is important and which information is unimportant. In that way, game group members who want to behave strategically should avoid mentioning accurate unshared and important information.

\section{Forms of strategic information sharing}

Because sharedness and importance are key characteristics of information, this new paradigm allows measuring various forms of strategic information sharing. Steinel et al. (2010) tested this idea by comparing group members with pro-self and pro-social motivations who played an information pooling game. More specifically, participants had to take photos of celebrities but had to share their limited information about when and where those celebrities will show up. Participants were rewarded for the number of pictures taken as a group (pro-socials) or as individuals (pro-selfs). Overall, pro-selfs shared less information than pro-socials, which is consistent with social dilemmas research showing that pro-socials contribute more to public good than pro-selfs (De Cremer \& Van Vugt, 1999). Pro-selfs also pooled less unshared information and less important information than pro-socials and lied more than pro-socials, especially about unshared information. Pro-selfs distorted both important and unimportant information, probably in an 
attempt to induce confusion about what is important to be discussed. In sum, this study showed that individuals driven by competitive motives behave more strategically than individuals with cooperative motives, as the former predominantly pool shared and unimportant information and withhold valuable and unshared information, be it important or unimportant.

The above-mentioned study suggests that group members are strategic when sharing their information because they know exactly what is the value of information for themselves and others. More direct evidence supporting this idea comes from a study conducted by Kimmerle et al. (2011). They developed an information exchange dilemma in which participants had the possibility to influence the value of self and others' information. They found that all participants avoided contributing information that would help others to obtain a higher benefit than the benefit they gained themselves, but this was especially pronounced for participants with a pro-self orientation. One explanation of this effect is that for pro-selfs, information is a source of power (Webster et al., 2008), and therefore, giving information of high value to others would be of high cost for themselves. This is in line with field studies showing that in organizations, competition leads employers to strategically distort their most valuable information (Mitusch, 2006).

Strategic information sharing also occurs when people distort their own information and exploit the accurate information provided by others. For example, in a situation of problem solving in dyads (Winter Survival Exercise - WSE), participants were asked to individually rank 12 items of information that were helpful in solving the problem. Then, they had to exchange information about their ranking with another participant. Participants who pursued competitive goals like aiming to outperform others (i.e., performance-approach goals) were less open to provide their true ranking to their partner than were participants who were simply motivated to do well on the task (i.e., mastery goals) (Poortvliet, Janssen, Van Yperen, \& Van de Vliert, 2007). In addition, participants with performance-approach goals also used the high-quality information received from their partners, more than participants with mastery goals.

Sometimes, when people are motivated to engage in strategic information sharing, they do not just hide or lie about valuable information, but they also engage in behaviors that are directly targeted to harm others' performance. In another WSE problem-solving task, individuals instructed to pursue performance goals were less willing than individuals with mastery goals to share accurate information, but also more willing to use thwarting behavior: They choose to administer a loud noise that prevented their partners to solve the problem (Poortvliet, Anseel, Janssen, Van Yperen, \& Van de Vliert, 2012).

An interesting, and yet understudied, facet of strategic information sharing refers to how much the competence or the expertise of the partner is taken into account. Logically, a competent partner should be considered as a reliable source of information, which should in turn facilitate information sharing. However, a great deal of research has shown that expert partners may also be considered as threatening opponents, when their competence is likely to question one's own competence (e.g., Butera \& Mugny, 2001; Quiamzade \& Mugny, 2009). For example, when a patient's diagnosis is hard to make, several doctors discuss the case in order to reach the best decision for the patient. During group discussions, some members might try to impose their point of view because they want to look smart and powerful. To this aim, they need to use subtle forms of deception, more so when interacting with high competent than with low competent partners. This is what Poortvliet et al. (2012) found in a second study: The level of competence of the exchange partner influenced the quality of information shared by the participants with competitive goals - they gave more blatantly inaccurate information to low competent than to high competent partners.

The partner's level of competence is thus an indicator of how much deception one could use, but also of how threatening the interaction could be. This latter situation can be encountered when group members are explicitly declared experts and have high competitive incentives 
(e.g., doctors who push for specific treatments because they defend the interests of some pharmaceutical companies). Expertise is considered a major resource, vital to the group's success (Bottger \& Yetton, 1988), but it could also lead to negative effects if experts simply want to look smarter than others, as is the case in competitive situations. In a recent study using a hidden profile (Toma, Vasiljevic, Oberlé, \& Butera, 2013), members were - or were not - explicitly declared experts and were instructed to pursue either competitive or cooperative goals (e.g., make the best decision for the group or for themselves). The results showed that group members who were declared experts and pursued competitive goals pooled and repeated even less unshared information than members who were not declared experts (Toma et al., 2013). This suggests that competitive motives counteract and even reverse the well-known positive effects of expertise on information sharing (Stasser et al., 1995). Expertise was only beneficial for information sharing only when group members pursued cooperative goals.

\section{Underlying mechanisms of strategic information sharing}

At this point, one might wonder why people behave strategically when motivated by competition. What are the underlying mechanisms that could explain the above-mentioned effects? One explanation is that competition leads people to mistrust other group members. Defined as the unwillingness to risk vulnerability to a person whose behavior is beyond one's control, mistrust (or fear of being exploited) is a good reason to engage in deceptive behavior. For example, fear of being exploited was found to be responsible for the withholding of accurate information in social decision-making (Steinel \& De Dreu, 2004) and for the withholding of unshared information in hidden profiles (Toma \& Butera, 2009).

Competition thus activates the fear of being exploited, but also the desire to exploit other people. Accordingly, Poortvliet et al. (2007) found that individuals pursuing performance-approach goals develop a strong exploitation orientation that explains why they share little valuable information and make use of the high-quality information obtained from others. Moreover, greed which is also related to exploitative intentions - explains why people provide inaccurate information to others in an information provision game (Steinel \& De Dreu, 2004). In all information exchange situations, competition activates tactical deception tendencies aimed at maintaining a positive self in other people's eyes. Indeed, Poortvliet et al. (2012) also showed that participants wanted to be seen as trustworthy, informed and competent, because in this way their partners can be convinced that the information they received was indeed valuable and accurate.

Competition also makes people more focused on standing out in the comparison of competences with others (Butera \& Mugny, 2001). For example, when experts are in competition with other experts, they want to prove that others' competence is inferior to their own (Quiamzade \& Mugny, 2009), and indeed, the devaluation of others' competence was found to be responsible for the negative effects of expertise and competition on unshared information pooling and repetitions (Toma, Gilles, \& Butera, 2013). In other words, experts' competence is threatened when in competition, and therefore, they tend to hinder others' competence by deliberately neglecting to mention valuable information.

To sum up, recent research provided convincing evidence that when group members are motivated by competition, they fear and denigrate their fellow members and thereby use various deceptive and exploitative strategies to share their information, which is not the case when members are motivated by cooperation.

\section{Strategic Information Use in Groups}

Group members can be strategic not only when sharing information, but also when using information received during group discussion. Previous research showed that even when all 
information is mentioned during group discussion, group members do not necessarily process this information efficiently (Van Knippenberg, de Dreu, \& Homan, 2004). Very often, people evaluate information received during group discussion in a biased way (Schulz-Hardt, Frey, Lüthgens, \& Moscovici, 2000): People favor information that is consistent, rather then inconsistent, with their initial preference ("preference effect"; Greitemeyer \& Schulz-Hardt, 2003) and evaluate their own information more favorably than others' information ("ownership bias"; Van Swol et al., 2003).

Several authors have recently questioned the merely cognitive origin of these biases (Faulmüller, Mojzisch, Kerschreiter, \& Schulz-Hardt, 2012; Toma et al., 2013) and argued that social motivations could play a central role in understanding why people favor their own information and information consistent with their preferences. Members who are motivated by cooperation should use information in a way that serves collective interests, while members who are motivated by competition should use information in a way that fosters individual outcomes (De Dreu et al., 2008). For example, when group members are motivated to convince others (like in competition) or to be understood by others (like in cooperation) they wish to get their own preference adopted by the group and therefore process information in a confirmatory way (Faulmüller et al., 2012). In the next section, we will provide supportive empirical evidence suggesting that by taking into account people's cooperative and competitive motivations, the preference effect and the ownership bias can be seen as strategic behaviors.

\section{Forms of strategic information use}

The preference effect, also called confirmation bias (Frey \& Schulz-Hardt, 2001), is an important indicator of information use. Whenever group members put into question their own or others' initial preferences, they need to use the available information in order to confirm or disconfirm their positions. At the same time, people instantly develop ownership of their ideas and prefer information that support and confirm them (for a review, see Frey \& Schulz-Hardt, 2001). Recent investigations suggest that the motivation to compete, as opposed to cooperate, with fellow members can enhance this bias.

There are two arguments supporting the idea that competition enhances the preference effect. First, competition motivates group members to avoid disconfirming their own preference. This is because people tend to react defensively when their own preferences are questioned, and especially with competitive motives (Darnon, Muller, Schrager, Pannuzzo, \& Butera, 2006; De Dreu \& van Knippenberg, 2005; Sommet et al., 2014). Second, competition motivates group members to avoid disconfirming others' erroneous preferences so as to impede them to find the correct decision and to keep the competitive advantage. Both effects were found in a study with real group discussions in which participants had to find the guilty person in a road accident case (Toma \& Butera, 2009). In this study, goal interdependence was manipulated (positive interdependence - i.e., cooperation versus negative interdependence - i.e., competition) and the number of times group members used a disconfirmation strategy during discussion was counted. The results showed that the disconfirmation of (one's own and others') preferences was lower under competition than under cooperation, which subsequently reduced decision quality in the competition condition.

A more direct test of how cooperative and competitive goals influence the preference effect comes from a study by Toma et al. (2013). In this study, participants received a fictitious discussion about a road accident investigation that contained consistent and inconsistent information with their initial preference. Participants were asked to evaluate this information and to reach a final decision. Cooperation versus competition and the presence versus absence of dissent (how diverse were individual members' preferences) were manipulated. Results showed that 
preference for consistent information was higher in competition than in cooperation, only when participants were informed that their preferences were in dissent with others' preferences (see also Hayek, Toma, Oberlé, \& Butera, 2014). This is because competition reinforces concerns for superiority and differentiation (Hornsey \& Jetten, 2004), and confirmation of one's own preference is an effective strategy to attain this goal. These results are consistent with the idea that the motivation to show one is right and others are wrong is responsible for the increase in confirmation of one's own preference (Sommet et al., 2014).

People can favor consistent over inconsistent information received during group discussion simply because consistent information resembles own information. It is now widely known that people evaluate themselves more favorably than others (Brown, 1986) and evaluate own information more favorably than others' information (Chernyshenko et al., 2003). This latter effect called ownership bias was found to influence group-decision quality (Van Swol et al., 2003). The ownership bias depends on whether others' information is consistent or inconsistent with their own. For example, Mojzisch et al. (2010) showed that the quality of own information was perceived as higher than the quality of others' information only when this information was consistent with participants' initial preference. More recently, Toma et al. (2013) suggested that group members' cooperative and competitive motives affect the extent to which the ownership bias occurs for consistent or inconsistent information. In a two-phase decision-making situation, participants had to reach an initial decision and then they evaluated the value of their own information, as well as that of others' consistent and inconsistent information while being instructed to cooperate or to compete with their fellow members. Participants instructed to compete judged their own information as more valuable than others' information, regardless of whether this information was consistent or inconsistent with initial decisions. Participants instructed to cooperate judged their own information as more valuable than others' consistent, but not inconsistent information. This suggests that cooperation leads people to acknowledge that others possess information (the inconsistent one) that is as valuable as their own information. Competition leads people to discard any type of information coming from others. As a consequence, members who competed with each other kept their initial incorrect decisions, while members who cooperated with others moved toward better decisions.

\section{Underlying mechanisms of strategic information use}

The same study directly tested whether the need to enhance the self is responsible for the abovementioned effects in competition. Self-enhancement reflects strivings to raise one's positive self-view and superiority (Alicke \& Sedikides, 2009). Because competition generally strengthens these concerns (Hornsey \& Jetten, 2004), competition motivates people to use preference confirmation as a self-enhancement strategy. Thus, Toma et al. (2013) found that self-enhancement predicted the use of preference confirmation of members motivated by competition who were confronted with the dissenting preferences of other group members. Interestingly, when confronted with members who witnessed a consensus on initial preferences, the same selfenhancement strategy predicted participants' propensity to use disconfirmation and to change their preferences. In other words, seeing that other members support the same preference as their own makes people motivated by competition changes their mind. This strengthens the idea that people behave strategically: They can stick to or change their preferences in order to cope with competition.

Self-enhancement is not the only mechanisms explaining the strategic use of confirmation. Under competition, confirmation of one's own initial preference can also serve a protection function (Butera \& Mugny, 1995, 2001), as it allows individuals to be reassured on them being right, and reduces the fear of being exploited by the competitors (Leyens, Dardenne, Yzerbyt, 
Scaillet, \& Snyder, 1999). In line with this idea, mistrust was found to mediate the impact of competitive (versus cooperative) goals on the use of confirmation during group discussion (Toma \& Butera, 2009). Mistrust and self-enhancement seem to be valid explanations for the preference confirmation, and perhaps even for the existence of the ownership bias in competitive settings. This suggests that in purely cooperative settings, people should be less biased in favor of own and consistent information.

\section{Conclusions and Future Directions}

Information processing in groups has long been seen as a cooperative process. However, group members were often found to neglect unshared information and to be unable to value others' information in an unbiased way. We argued that by taking into account group members' cooperative and competitive motives, information sharing and use in groups could be seen as strategic behavior rather than as biased processing. We reviewed and integrated the latest developments in the literature investigating different forms and underlying mechanisms of strategic information sharing and use in group decision-making. Our analysis suggests that with regard to information sharing, group members are more strategic when motivated by competition than by cooperation: They withhold, lie about, distort, and exploit information because they feel greed and mistrust toward fellow members.

With regard to information use, group members behave strategically when motivated by competition as opposed to cooperation. People can confirm or disconfirm their preferences whenever this helps enhancing the competitive self. The findings reviewed here suggest that under competitive incentives, information processing is impaired and that cooperation, although not sufficient, is needed for effective group decision-making.

The empirical evidence on which these conclusions are derived comes essentially from experimental studies with ad-hoc groups performing tasks with relatively low implications for its members. Therefore, future research should focus on real groups in organizational and educational settings in which the cooperative and competitive motives could be induced by features of the relevant context (e.g., norms, time pressure, rewards, and criteria for evaluation). There has been little research devoted to study how external factors influence group members' motivation and group information processing (for an exception, see Hayek, Toma, Oberlé \& Butera 2015), and we hope that future research will fill this gap.

Another important direction for future research is to investigate the impact of group composition in terms of pro-social and pro-self motivation. How many pro-social members are needed in a group to induce a cooperative atmosphere? It might be that the answer largely depends on the position of those particular members (how much they are trusted, admired, and respected). Previous research suggests that the effect of a particular members' motivation depends on the power of that person to influence the group (Ten Velden, Beersma, \& De Dreu, 2010). However, this research only investigated the effect of epistemic motivation, and we don't know whether the same holds for the social motivation.

It is also important to investigate the joint effect of social and epistemic motivation. Cooperative motives might not always be sufficient to make group members less biased toward shared and preference-consistent information if they are not accompanied by epistemic motivation (De Dreu et al., 2008). One way of inducing both motivations is to create intergroup competition, which should induce higher information processing and better decision quality (Nijstad \& De Dreu, 2012).

We hope that the present review will stimulate further research examining how different forms of motivation affect strategic information processing beyond the more traditional approaches to group decision-making. 


\section{Short Biographies}

Claudia Toma is associate professor at Solvay Brussels School of Economics and Management, Université libre de Bruxelles, Belgium and member of Tilburg Institute for Behavioral Economics Research, Tilburg University. Her research interests include information processing in group decision-making and egocentric biases in judgment.

Fabrizio Butera is a full professor at the Department of Social Psychology, University of Lausanne, Switzerland. His research is concerned with the study of social change, from the structural processes founding social influence (power, norms, interdependence, etc.) to the cognitive and motivational mechanisms that determine individual change.

\section{Notes}

* Correspondence: Centre Emile Bernheim, Solvay Brussels School of Economics and Management, Université libre de Bruxelles. Email: claudia.toma@ulb.ac.be.

Some of the research reported in this article were funded by the Swiss National Science Foundation.

\section{References}

Alicke, M. D., \& Sedikides, C. (2009). Self-enhancement and self-protection: What they are and what they do. European Review of Social Psychology, 20, 1-48.

Bottger, P. C., \& Yetton, P. W. (1988). An integration of process and decision scheme explanations of group problem solving performance. Organizational Behavior and Human Decision Processes, 42, 234-249.

Brown, J. D. (1986). Evaluations of self and others: Self-enhancement biases in social judgments. Social Cognition, 4, 353-376.

Butera, F., \& Mugny, G. (1995). Conflict between incompetences and influence of a low-competence source in hypothesis testing. European Journal of Social Psychology, 25, 457-462.

Butera, F., \& Mugny, G. (2001). Conflicts and social influences in hypothesis testing. In C. De Dreu, \& N. De Vries (Eds.), Group Consensus and Minority Influence: Implications for Innovation (pp. 160-182). Oxford: Blackwell.

Chernyshenko, O. S., Miner, A. G., Baumann, M. R., \& Sniezek, J. A. (2003). The impact of information distribution, ownership, and discussion on group member judgment: The differential cue weighting model. Organizational Behavior and Human Decision Processes, 91, 12-25.

Darnon, C., Muller, D., Schrager, S., Pannuzzo, N., \& Butera, F. (2006), Mastery and performance goals predict epistemic and relational conflict regulation. Journal of Educational Psychology, 98, 766-776.

De Cremer, D., \& Van Vugt, M. (1999). Social identification effects in social dilemmas: A transformation of motives. European Journal of Social Psychology, 29, 871-893.

De Dreu, C. K. W., Nijstad, B. A., \& van Knippenberg, D. (2008). Motivated information processing in group judgment and decision making. Personality and Social Psychology Review, 12, 22-49.

De Dreu, C. K. W., \& Van Knippenberg, D. (2005). The possessive self as a barrier to constructive conflict management: Effects of mere ownership, process accountability, and self-concept clarity on competitive cognitions and behavior. Journal of Personality and Social Psychology, 89, 345-357.

Dweck, C. S. (1986). Motivational processes affecting learning. American Psychologist, 41, 1040-1048.

Elliot, A. J., \& McGregor, H. A. (2001). A 2*2 achievement goal framework. Journal of Personality and Social Psychology, 80, 501-519.

Faulmüller, N., Kerschreiter, K., Mojzisch, A., \& Schulz-Hardt, S. (2010). Beyond group-level explanations for the failure of groups to solve hidden profiles: The individual preference effect revisited. Group Processes \& Intergroup Relations, 13, 653-671.

Faulmüller, N., Mojzisch, A., Kerschreiter, K., \& Schulz-Hardt, S. (2012). Do You want to convince me or to be understood? Preference-consistent information sharing and its motivational determinants. Personality and Social Psychology Bulletin, 38, 1685-1697.

Frey, D., \& Schulz-Hardt, S. (2001). Confirmation bias in group information seeking and its implications for decision making in administration, business and politics. In F. Butera, \& G. Mugny (Eds.), Social Influence in Social Reality (pp. 53-74). Göttingen: Hogrefe \& Huber Publishers.

Greitemeyer, T., \& Schulz-Hardt, S. (2003). Preference-consistent evaluation of information in the hidden profile paradigm: Beyond group-level explanations for the dominance of shared information in group decisions. Journal of Personality and Social Psychology, 84, 322-339. 
Harackiewicz, J. M., \& Sansone, C. (1991). Goals and intrinsic motivation: You can get there from here. In P. R. Pintrich, \& M. L. Maehr (Eds.), Advances in Motivation and Achievement (Vol. 7): Goals and Self-Regulatory Processes (pp. 21-49). Greenwich, CT: JAI Press.

Hayek, A. S., Toma, C., Oberlé, D., \& Butera, F. (2015). Grading hampers cooperative information sharing in group problem solving. Social Psychology, in press.

Hayek, A. S., Toma, C., Oberlé, D., \& Butera, F. (2014). The effect of grades on the preference effect: Grading reduces consideration of disconfirming evidence. Basic and Applied Social Psychology, 36, 544-552.

Hinsz, V. B., Tindale, R. S., \& Vollrath, D. A. (1997). The emerging conceptualization of groups as information processors. Psychological Bulletin, 121, 43-64.

Hornsey, M. J., \& Jetten, J. (2004). The individual within the group: Balancing the need to belong with the need to be different. Personality and Social Psychology Review, 8, 248-264.

Johnson, D. W., \& Johnson, R. (1989). Cooperation and Competition: Theory and Research. Edina, MN: Interaction Book Company.

Kimmerle, J., Wodzicki, K., Jarodzka, H., \& Cress, U. (2011). Value of information, behavioral guidelines, and social value orientation in an information-exchange dilemma. Group Dynamics: Theory, Research, and Practice, 15, 173-186.

Larson, J. R., Christensen, C., Abbott, A. S., \& Franz, T. M. (1996). Diagnosing groups: Charting the flow of information in medical decision-making teams. Journal of Personality and Social Psychology, 71, 315-330.

Leyens, J.-P., Dardenne, B., Yzerbyt, V., Scaillet, N., \& Snyder, M. (1999). Confirmation and disconfirmation: Their social advantages. In W. Stroebe, \& M. Hewstone (Eds.), European Review of Social Psychology (Vol. 10, pp. 199-230). Chichester: Wiley.

Lu, L., Yuan, Y., \& McLeod, P. L. (2012). Twenty-five years of hidden profile studies: A meta-analysis. Personality and Social Psychology Review, 16, 54-75.

Messick, D. M., \& McClintock, C. G. (1968). Motivational basis for choice in experimental games. Journal of Experimental Social Psychology, 4, 1-25.

Mitusch, K. (2006). Non-commitment in performance evaluation and the problem of information distortions. Journal of Economic Behavior \& Organization, 60, 507-525.

Mojzisch, A., Grouneva, L., \& Schulz-Hardt, S. (2010). Biased evaluation of information during discussion: Disentangling the effects of preference consistency, social validation, and ownership of information. European Journal of Social Psychology, 40, 946-956.

Nijstad, B. A., \& Dreu, C. K. W. de (2012). Motivated information processing in organizational teams: Progress, puzzles, and prospects. Research in Organizational Behavior, 32, 87-111.

Pearsall, M. J., Christian, M. S., \& Ellis, A. P. J. (2010). Motivating interdependent teams: Individual rewards, shared rewards, or something in between? Journal of Applied Psychology, 95, 183-191.

Poortvliet, P. M., Anseel, F., Janssen, O., Van Yperen, N. W., \& Van de Vliert, E. (2012). Perverse effects of otherreferenced performance goals in an information exchange context. Journal of Business Ethics, 106, 401-414.

Poortvliet, P. M., Janssen, O., Van Yperen, N. W., \& Van de Vliert, E. (2007). Achievement goals and interpersonal behavior: How mastery and performance goals shape information exchange. Personality and Social Psychology Bulletin, 33, 1435-1447.

Quiamzade, A., \& Mugny, G. (2009). Social influence and threat in confrontations between competent peers. Journal of Personality and Social Psychology, 97, 652-666.

Reimer, T., Reimer, A., \& Czienskowski, U. (2010). Decision-making groups attenuate the discussion bias in favor of shared information: A meta-analysis. Communication Monographs, 77, 122-143.

Schulz-Hardt, S., Frey, D., Lüthgens C., \& Moscovici, S. (2000). Biased information search in group decision making. Journal of Personality and Social Psychology, 78, 655-669.

Sommet, N., Darnon, C., Mugny, G., Quiamzade, A., Pulfrey, C., Dompnier, B., \& Butera, F. (2014). Performance goals in conflictual social interactions: Toward the distinction between two modes of relational conflict regulation. British Journal of Social Psychology, 53, 134-153.

Stasser, G., \& Stewart, D. (1992). Discovery of hidden profiles by decision-making groups: Solving a problem versus making a judgment. Journal of Personality and Social Psychology, 63, 426-434.

Stasser, G., Stewart, D. D., \& Wittenbaum, G. M. (1995). Expert roles and information exchange during discussion: The importance of knowing who knows what. Journal of Experimental Social Psychology, 31, 244-265.

Stasser, G., Taylor, L. A., \& Hanna, C. (1989). Information sampling in structured and unstructured discussions of three- and six-person groups. Journal of Personality and Social Psychology, 57, 67-78.

Stasser, G., \& Titus, W. (1985). Pooling of unshared information in group decision making: Biased information sampling during discussion. Journal of Personality and Social Psychology, 48, 1467-1478.

Stasser, G., \& Titus, W. (1987). Effects of information load and percentage of shared information on the dissemination of unshared information during group discussion. Journal of Personality and Social Psychology, 53, 81-93.

Stasser, G., \& Titus, W. (2003). Hidden profiles: A brief history. Psychological Inquiry, 14, 304-313. 
Steinel, W., \& De Dreu, C. K. W. (2004). Social motives and strategic misrepresentation in social decision making. Journal of Personality and Social Psychology, 86, 419-434.

Steinel, W., Utz, S., \& Koning, L. (2010). The good, the bad and the ugly thing to do when sharing information: Revealing, concealing and lying depend on social motivation, distribution and importance of information. Organizational Behavior and Human Decision Processes, 113, 85-96.

Stewart, D. D., \& Stasser, G. (1998). The sampling of critical, unshared information in decision-making groups: The role of an informed minority. European Journal of Social Psychology, 28, 95-113.

Ten Velden, F. S., Beersma, B., \& De Dreu, C. K. W. (2010). It takes one to tango: The effects of dyads' epistemic motivation composition in negotiation. Personality and Social Psychology Bulletin, 36, 1454-1466.

Toma, C., Bry, C., \& Butera, B. (2013). Because I'm worth it! (More than others...): Cooperation, competition and ownership bias in group-decision making. Social Psychology, 44, 248-255.

Toma, C., \& Butera, F. (2009). Hidden profiles and concealed information: Strategic information sharing in group decision making. Personality and Social Psychology Bulletin, 35, 793-806.

Toma, C., Gilles, I., \& Butera, F. (2013). Strategic use of preference confirmation in group decision making: The role of competition and dissent. British Journal of Social Psychology, 52, 44-63.

Toma, C., Vasiljevic, D., Oberlé, D., Augustinova, M., \& Butera, F. (2012). Le traitement motivé de l'information dans la prise de décision en groupe: Le cas du paradigme des "profils cachés ". L'Année Psychologique, 112, 665-695.

Toma, C., Vasiljevic, D., Oberlé, D., \& Butera, F. (2013). Assigned experts with competitive goals withhold information in group decision making. British Journal of Social Psychology, 52, 161-172.

Van Knippenberg, D., de Dreu, C. K. W., \& Homan, A. C. (2004). Work group diversity and group performance: An integrative model and research agenda. Journal of Applied Psychology, 89, 1008-1022.

Van Lange, P. A. M., Otten, W., De Bruin, E., \& Joireman, J. A. (1997). Development of prosocial, individualistic, and competitive orientations: Theory and preliminary evidence. Journal of Personality and Social Psychology, 73, 733-746.

Van Swol, L. M., Savadori, L., \& Sniezek, J. A. (2003). Factors that may affect the difficulty of uncovering hidden profiles. Group Processes and Intergroup Relations, 6, 285-304.

Webster, J., Brown, G., Zweig, D., Connelly, C. E., Brodt, S., \& Sitkin, S. (2008). Beyond knowledge sharing: Withholding knowledge at work. In J. Martocchio, H. Liao, \& A. Joshi (Eds.), Research in Personnel and Human Resources Management (Vol. 27, pp. 1-37). Bingley, England: Emerald Group Publishing.

Wittenbaum, G. M., Hollingshead, A. B., \& Botero, I. C. (2004). From cooperative to motivated information sharing in groups: Moving beyond the hidden profile paradigm. Communication Monographs, 71, 286-310.

Wittenbaum, G. M., Hubbell, A. P., \& Zuckerman, C. (1999). Mutual enhancement: Toward an understanding of the collective preference for shared information. Journal of Personality and Social Psychology, 77, 967-978. 